http://jmscr.igmpublication.org/home/ ISSN (e)-2347-176x ISSN (p) 2455-0450 crossref DOI: https://dx.doi.org/10.18535/jmscr/v9i7.28

Journal Of Medical Science And Clinical Research

\title{
Technical Refinements in Posterior Interosseous Artery flap
}

\author{
Authors
}

\section{Dr Dharanipriya Arikrishnan, Dr Jaganmohan Janardhanam*, Dr Ashok Kumar Ranganathan}

Rajiv Gandhi Government General Hospital \& Madras Medical College, Chennai

*Corresponding Author

\section{Dr Jaganmohan Janardhanam}

\begin{abstract}
Introduction: Hand injuries continue to be a major occupational hazard and a frequently associated injury in road traffic accidents requiring flap cover for soft tissue defects. Various local flaps, regional flaps, distant flaps, and free flaps are used for covering hand defects. Posterior Interosseous Artery (PIA) Flap is a reliable regional flap for such defects. It is a reverse pedicled fasciocutaneous flap, based on the anastomosis between Posterior and Anterior Interosseous arteries near distal Radio Ulnar Joint. In our present study, we have documented a consistent branch from the ulnar artery, running around the neck of the ulna and anastomosing with the PIA which enhances flap vascularity when carefully retained. We have designed the flap based on mid-forearm perforator from PIA which avoids encountering PIN branches present proximally. The perforator is eccentrically placed in the flap design, thus allowing the proximal forearm skin to be raised in the flap without compromising the reach of the flap

Aim: To study the technical refinements in PIA flap and to recapitulate the versatility of PIA flap for various defects of distal forearm and hand.

Methodology: A prospective study was conducted over a period of 15 months to include 15 cases of distal forearm and hand defects that could be covered with PIA flap. The patients were observed for outcomes.

Results: Fifteen cases were included in this study over a span of 15 months. The average age was 41.9 years. Posttraumatic defects in the dorsum of hand, fingers, thumb, and volar aspect of the distal forearm; Post burn contractures in the palm (camphor burns), 1st web space, and thumb; and post excisional defect of tumor in hand were included. None of the flaps had any partial or total necrosis. One patient had flap edema (6.67\%) and another patient had venous congestion (6.67\%) of the flap which subsided by conservative management.

Conclusion: PIA is a versatile and reliable flap for the defects in the distal forearm and hand. Mid-forearm perforator can be chosen whenever feasible with appropriate flap design to avoid encountering PIN branches. Vascularity can be enhanced by maintaining the communicating vessels from the ulnar artery around the neck of the ulna.
\end{abstract}

Keywords: dorsal interosseous artery flap, distally based island flap, distally based fasciocutaneous flap, hand reconstruction, distal forearm reconstruction, post-burns reconstruction of hand.

\section{Introduction}

Hand injuries continue to be a major occupational hazard and a frequently associated injury in road traffic accidents ${ }^{(1)}$. Soft tissue defects of the hand require early flap cover to protect exposed neurovascular structures, tendons \& bone, thus ensuring their vascularity, preventing infection, allowing early mobilization, and a good functional outcome finally. Various local flaps, regional flaps, distant flaps, and free flaps are used for covering hand defects. Local flaps are small flaps which might not meet the requirements of larger defects. Distant flaps have a multi-staged procedure and require high patient compliance. Free flaps are technically demanding. Most of the regional flaps have the advantage of being a single 
staged procedure $^{(2)}$ in general which provides adequate tissue for complete cover of the defect.

Posterior Interosseous Artery (PIA) Flap has become a preferred flap since its introduction by Zancolli and Angrigiani in $1986^{(3)}$. It is a reverse pedicle fasciocutaneous flap (Mathes \& Nahai type B). It is based on the anastomosis between Posterior and Anterior Interosseous arteries near distal Radio Ulnar Joint ${ }^{(4)}$. The flap receives multiple septocutaneous branches from the PIA running between Extensor Digiti Minimi (EDM) and Extensor Carpi Ulnaris (ECU) ${ }^{(5)}$. A relatively larger flap can be harvested without sacrificing the two major arteries ${ }^{(6)}$ of hand and can even be harvested when these are injured.Extended flaps have been described based on the continuation of PIA in the fifth extensor compartment (ECA) and further anastomosis with Dorsal Intercarpal Arch (DIA) $)^{(7)}$.

In our present study, we have documented a consistent branch from the ulnar artery, running around the neck of the ulna and anastomosing with the PIA. Identifying this communication and preserving this branch shifts the pivot point 0.5 $\mathrm{cm}$ further proximally. But it serves for better vascularity of the retrograde PIA flap, without compromising the reach of the flap when planned appropriately.

The Posterior Interosseous Nerve (PIN) located lateral to the PIA, sends branch to ECU which is closely associated with the most proximal relevant perforator. Buchler and Frey ${ }^{(8)}$ had described three types of relationship of the ECU branch of PIN with the most proximal relevant perforator of PIA in which type $\mathrm{C}$ pattern would require neurotomy and repair of the ECU branch supplying PIN if the flap was planned on the proximal perforator. Such complication can be avoided by choosing the midforearm perforator from PIA. The reach of the flap is not compromised by this as the perforator can be eccentrically placed in the flap design and thus the proximal forearm skin can be raised in the flap.

Another disadvantage of conventional PIA flap is its bulkiness as a fasciocutaneous flap for the very thin dorsal skin of the hand. The other available Radial forearm flap can be harvested both suprafascially and subfascially. Likewise, we have harvested the flap proximal to the perforator without fascia to have a more supple and pliable cover to the distal end of the defect. These modifications of the promising PIA flap are described in this article.

\section{Aims \& Objective}

1. To study the feasibility of harvesting a more pliable suprafascial flap proximal to the perforator

2. To redefine the pivot point proximally for better vascularity.

3. To assess the feasibility of choosing midforearm perforator to avoid encountering the branch of PIN to ECU without affecting the reach of the flap

4. To recapitulate the versatility of PIA flap for various defects of distal forearm and hand

\section{Material and Methods}

A prospective study was conducted between January 2019 and March 2020 at our institute. A total number of 15 cases were included. Complete general and local evaluations were done. Those patients with a distal forearm and hand defects that could be covered with PIA flap were included. Written and informed consent was obtained from all patients.

\section{Inclusion Criteria}

- Volar wrist defects

- Palmar and dorsal hand defects

- Dorsum of Finger defects proximal to PIP joint

- Thumb defects

- 1 st web space contracture

\section{Exclusion criteria}

- Uncontrolled diabetes mellitus

- Patient with Peripheral vascular disease

\section{Surgical Procedure}

Pre-operative Doppler marking of perforator was done. Four cases were done under general 
anesthesia and 11 cases were done under regional block.

In case of trauma, the defects were debrided adequately and thorough wash was given. Then the defect to be covered by flap was assessed. In cases of contracture, an adequate release was done and the defect to be covered by flap was measured. For skin tumors, the flap was planned after wide local excision

The vascular axis of the flap was marked from the lateral epicondyle to distal radio-ulnar joint (DRUJ). A point $2 \mathrm{~cm}$ proximal to DRUJ along this line is the conventional pivot point. By planning in reverse, the flap was marked around the perforator in the mid-forearm. This perforator is usually $1 \mathrm{~cm}$ distal to the midpoint of the line joining the lateral epicondyle to DRUJ. The location of perforator was confirmed by a hand held Doppler. The perforator can be eccentrically placed in the flap design (Figure 1), enabling the proximal forearm skin to be raised in the flap, thus not compromising the distal reach of the flap.

Surgery was done under loupe magnification. The radial incision was made and the fascia over the EDC was encountered [Extensor Carpi Radialis Longus (ECRL)/ Extensor Carpi Radialis Brevis (ECRB) too if the flap is large]. As we dissected radial to ulnar the septum between EDC and EDM was cut and dissection was done until the septum between EDM and ECU was reached. The ulnar incision was made and dissected towards the septum between ECU and EDM. The fascia over extensor muscles was included in the flap distal to the perforator (Figure $2 \& 3$ ). A linear incision was extended distally from the flap towards the pivot point to dissect the pedicle. Dermal flaps on either side were raised and retracted and the linear adipo-fascial pedicle was raised on the septum with PIA. Distally a dorsal branch from the ulnar artery was always encountered anastomosing with the PIA, which was carefully preserved (Figure 4). The pedicle dissection was stopped here, thus shifting the pivot point $0.5 \mathrm{~cm}$ further proximal to the conventional pivot point. The proximal end of PIA was ligated and divided proximal to the chosen mid perforator. The septum between ECU and EDM was raised as the pedicle (contains PIA vessel), by cutting its attachment to the bone, deep to the PIA vessels. The flap was tunneled to the defect and inset given with 3-0 Prolene. If there is slight tension to inset at the defect margins, further mobilization for $3 \mathrm{~mm}$ can be gained by incising the periosteum transversely over ulna proximal to the communicating ulnar branch thus mobilizing it distally along with periosteum of ulna. A Segmüller drain was placed. The thin pliable flap proximal to the perforator which was raised suprafascially fit well on the fingers, thumb, first web and palm where thick flaps are not desired.

The secondary raw area was grafted with splitthickness skin graft and tie over dressing was applied. When the width of the donor defect was less, primary closure was done. The incision between the flap and defect was closed primarily and grafted with split-thickness skin graft only at the $180^{\circ}$ turn of the pedicle if it was getting compressed with primary suturing.

The flap was dressed with loose fluffy dressing and splinted with volar POP slab positioning wrist at 30 degrees extension and MCP Joint at 90 degrees flexion.

\section{Post-operative Care}

The flap was monitored for any complications in the postoperative period. Hand elevation was given. The drain was removed in 2-3 days. The sutures were removed after 2 weeks and mobilization was started. Graft dressing on the donor site was changed after 5 days.

\section{Case Illustration 1}

A 36-year female had a history of accidental scald burns to left forearm and hand 4 years ago, which healed by secondary intention. On examination, the patient had Z-contracture (Hyperextension of MCP and flexion of IP joint) of thumb (Figure 5). The flap was marked. The flap proximal to the perforator was elevated suprafascially (Figures 2 $\& 3)$. Figure 2 shows the deep fascia covering the 


\section{JMSCR Vol||09||Issue||07||Page 155-168||July}

proximal part of the secondary raw area. Distal to the perforator deep fascia was included with the flap. Figure 3 shows the elevated flap with deep fascia included distal to the perforator. The part of the flap which would reach the distal part of the defect was raised as a thin pliable suprafascial flap, and it covered the 1st web space and proximal phalanx comfortably (Figure 5). Postoperatively, the patient did not require any secondary debulking procedure and was able to freely oppose the thumb (Figure 5).

\section{Results}

Fifteen cases done in our department in a span of 15 months were included in this study (Table 1 ). Eight out of the 15 cases were male $(53.3 \%)$ and the remaining 7 were female $(46.7 \%)$. The average age was 41.9 years. The majority of the cases ( 9 patients) were post-traumatic defects in the dorsum of hand, fingers, thumb, and volar aspect of the distal forearm which were debrided in emergency (8 patients) or elective (one patient) and immediate cover with PIA flap were done. One-third of the cases ( 5 patients) had post burn contractures in the palm (camphor burns), 1st web space, and thumb. The contractures were released and the defect was covered with PIA flap. One case of recurrent dermatofibrosarcoma protuberans of the hand underwent wild local excision and the PIA flap cover. None of the flaps had any partial or total necrosis. One patient had flap edema $(6.67 \%)$ and another patient had venous congestion $(6.67 \%)$ of the flap which subsided by conservative management.

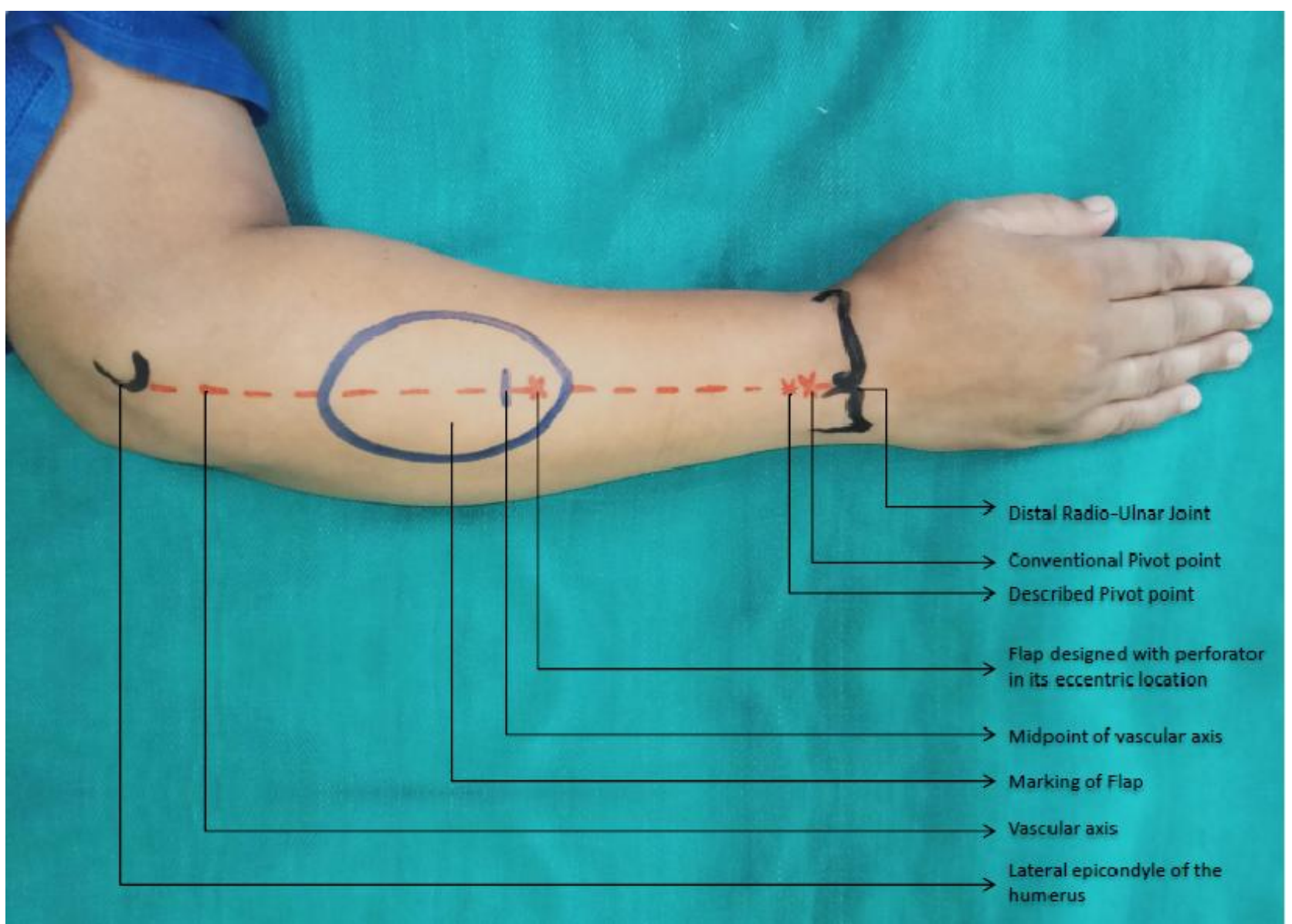

Figure 1: Markings showing the vascular axis, conventional and proposed pivot point, flap design with perforator in its eccentric location 


\section{JMSCR Vol||09||Issue||07||Page 155-168||July}

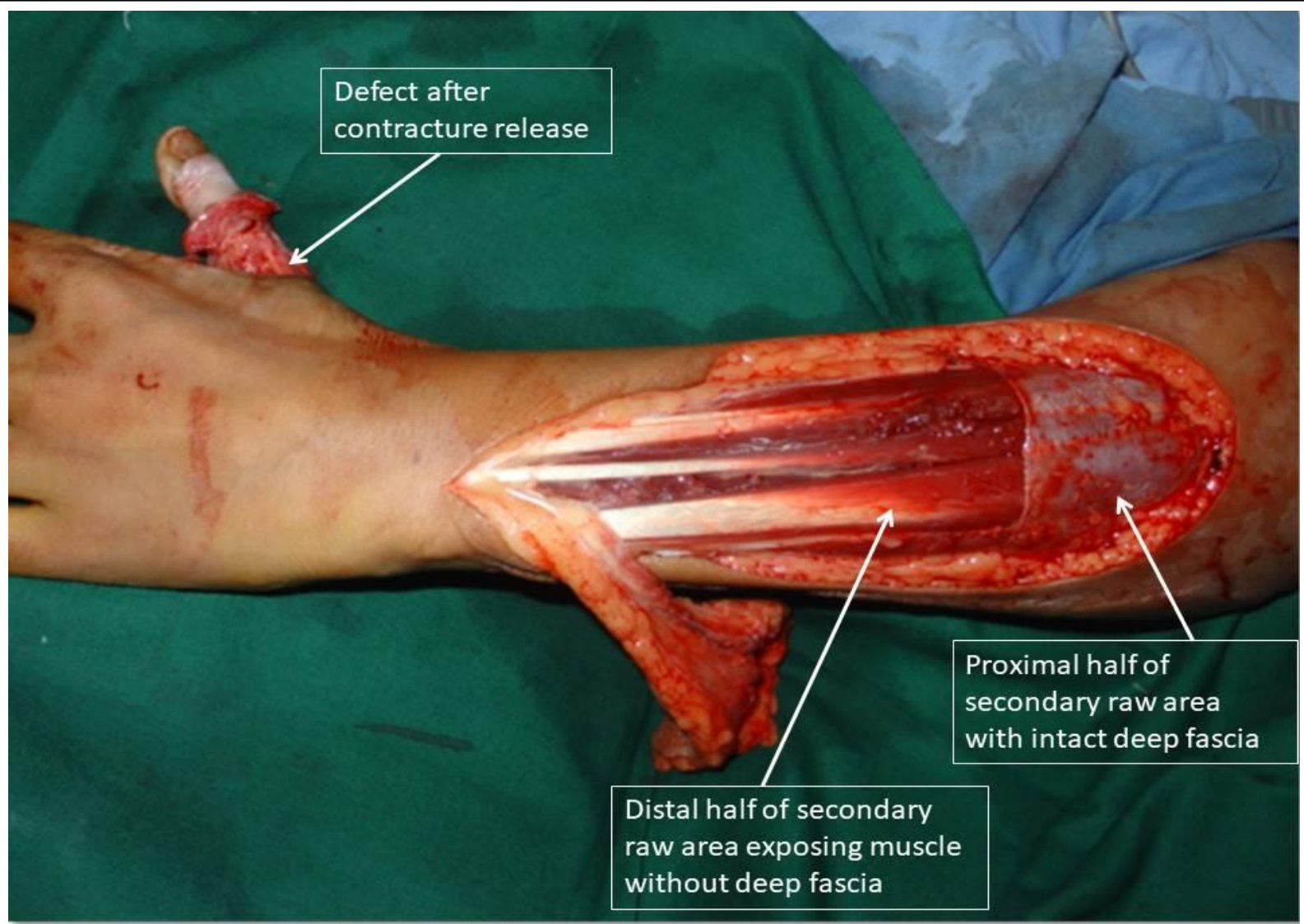

Figure 2: Image showing the defect in thumb after contracture release and the elevated flap; Deep fascia was left intact in the proximal half of the secondary raw area

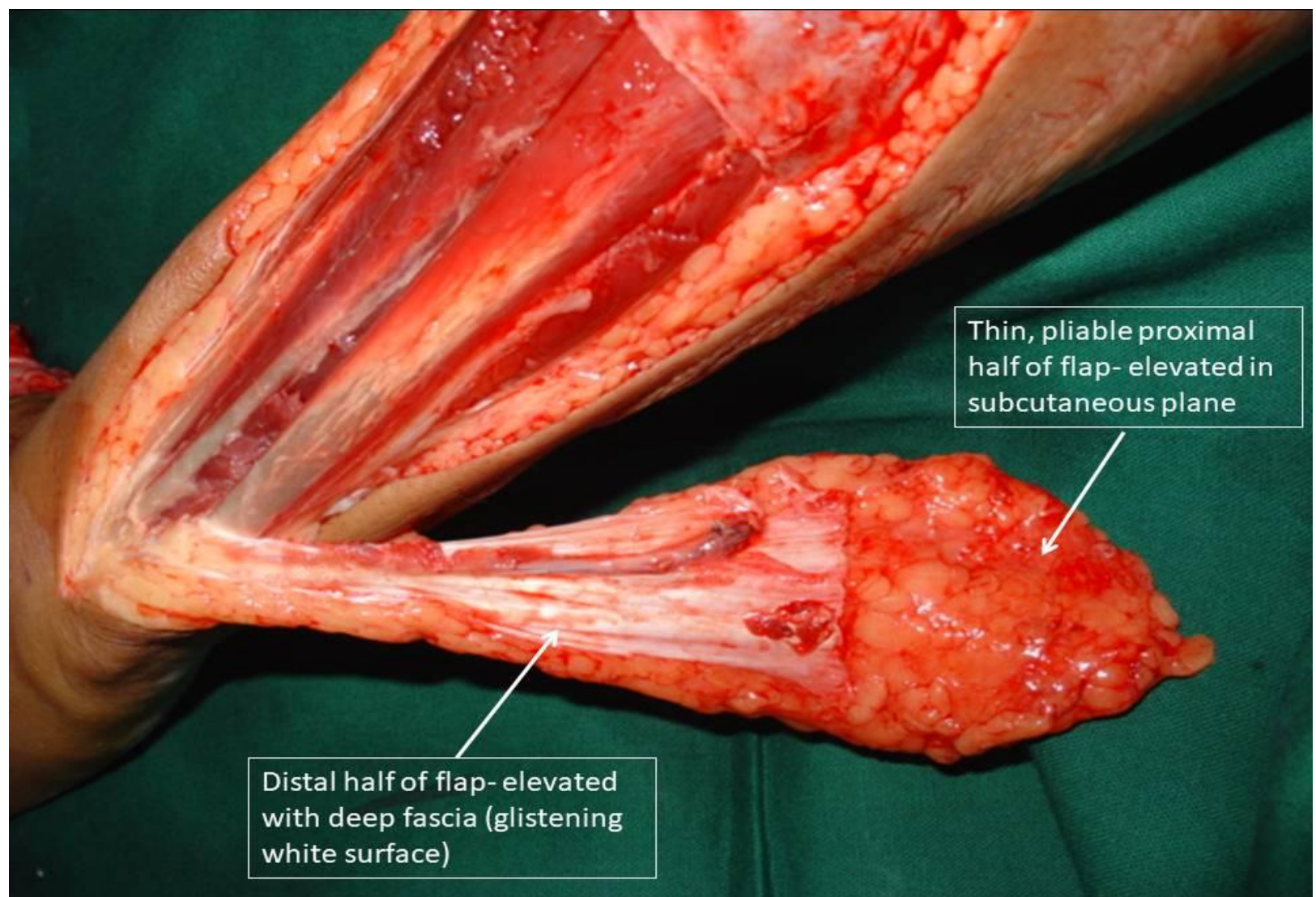

Figure 3: Image showing the elevated flap without deep fascia proximal to the perforator. With the perforator inclusion, the flap and the pedicle were elevated with the deep fascia 


\section{JMSCR Vol||09||Issue ||07||Page 155-168||July}
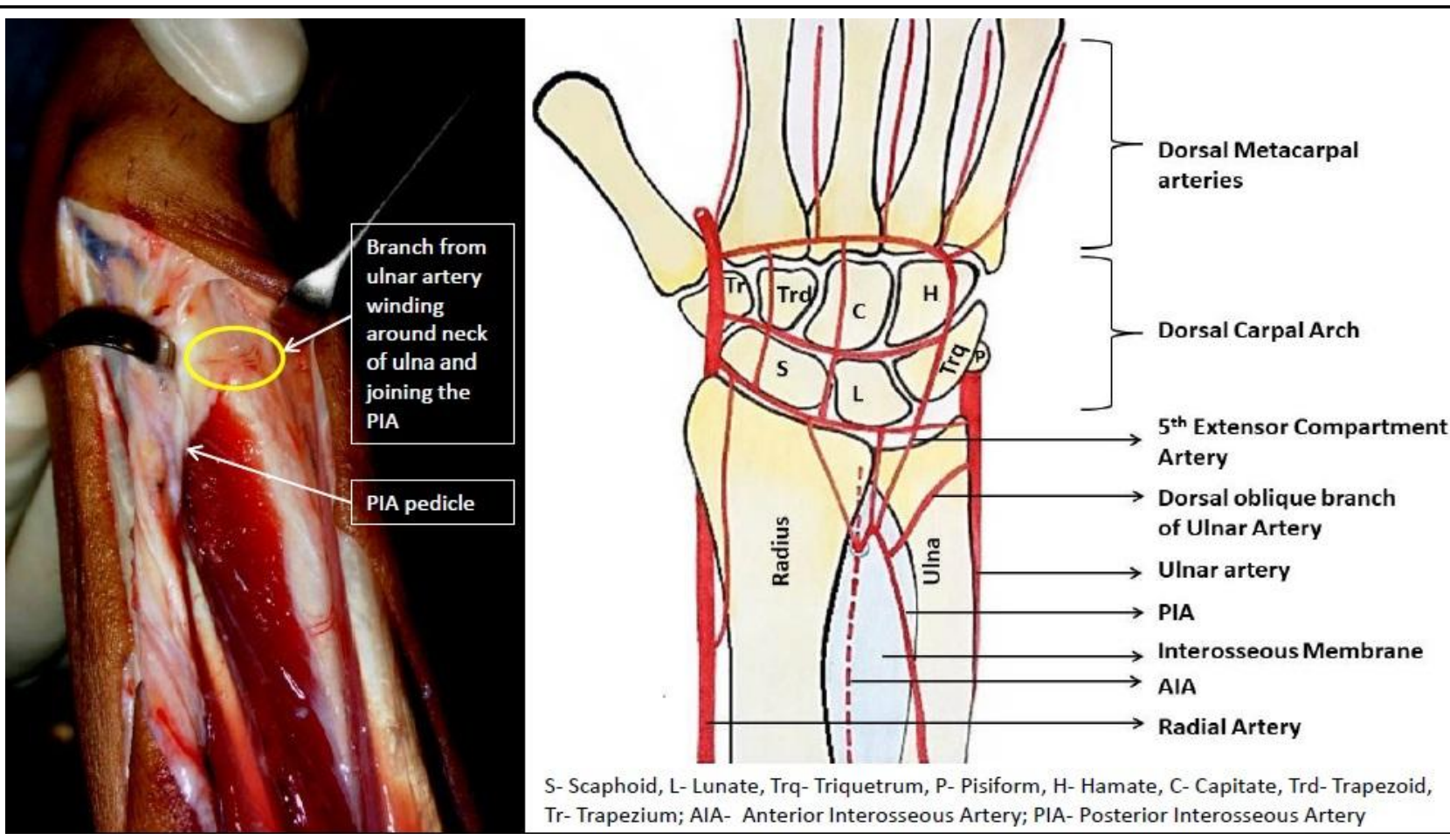

S- Scaphoid, L- Lunate, Trq- Triquetrum, P- Pisiform, H- Hamate, C-Capitate, Trd- Trapezoid, Tr-Trapezium; AIA- Anterior Interosseous Artery; PIA- Posterior Interosseous Artery

Figure 4: Image showing dorsal branch from ulnar artery winding around the neck of ulnar to join the PIA (Left) and diagrammatic illustration of branches and anastomoses of PIA near the wrist joint (Right)

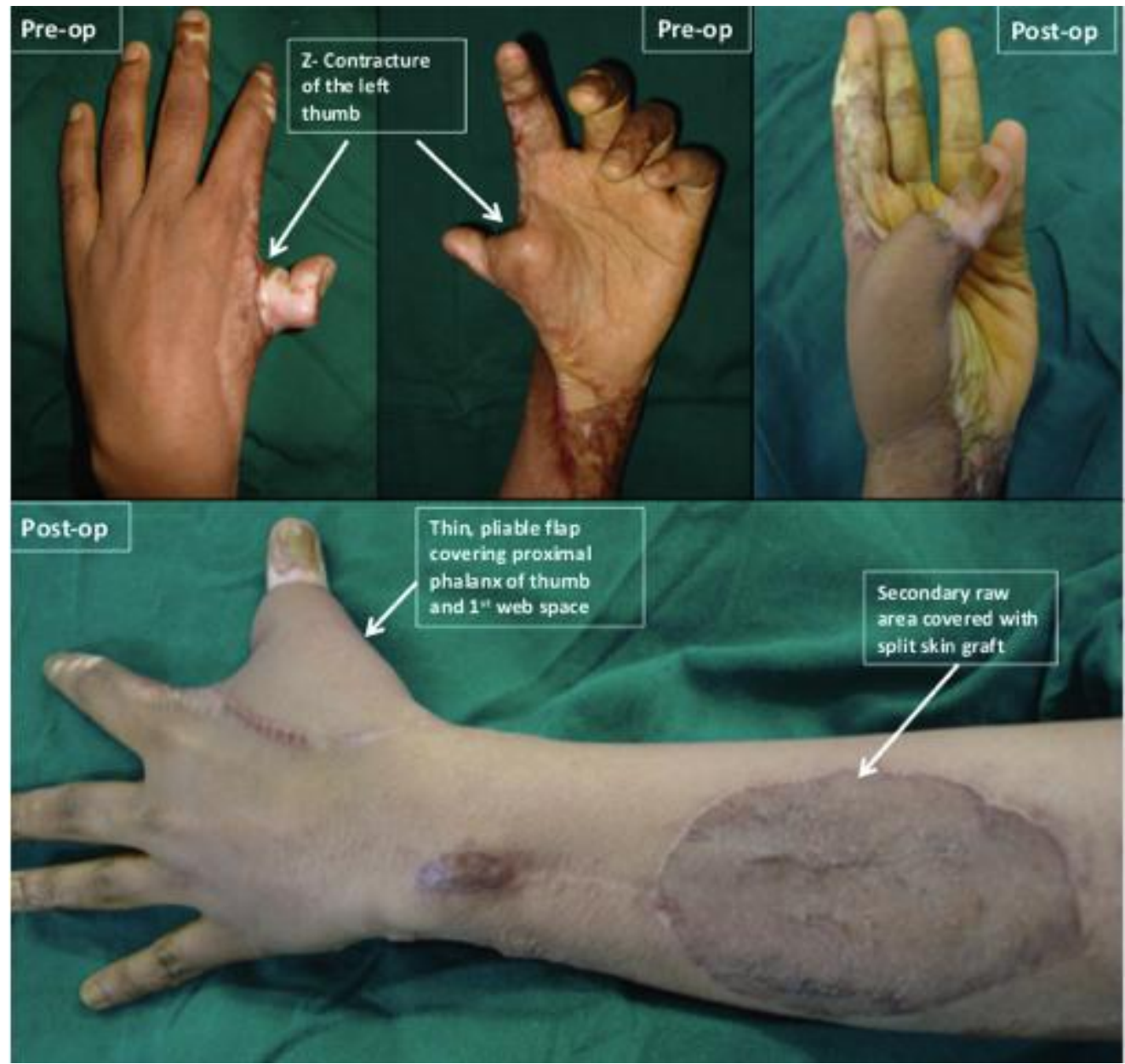

Figure 5: Case 1- Contracture release of post-burnleftthumb Z-contracture and PIA flap cover of thumb and $1^{\text {st }}$ webspace 


\section{JMSCR Vol||09||Issue ||07||Page 155-168||July}

\section{1}

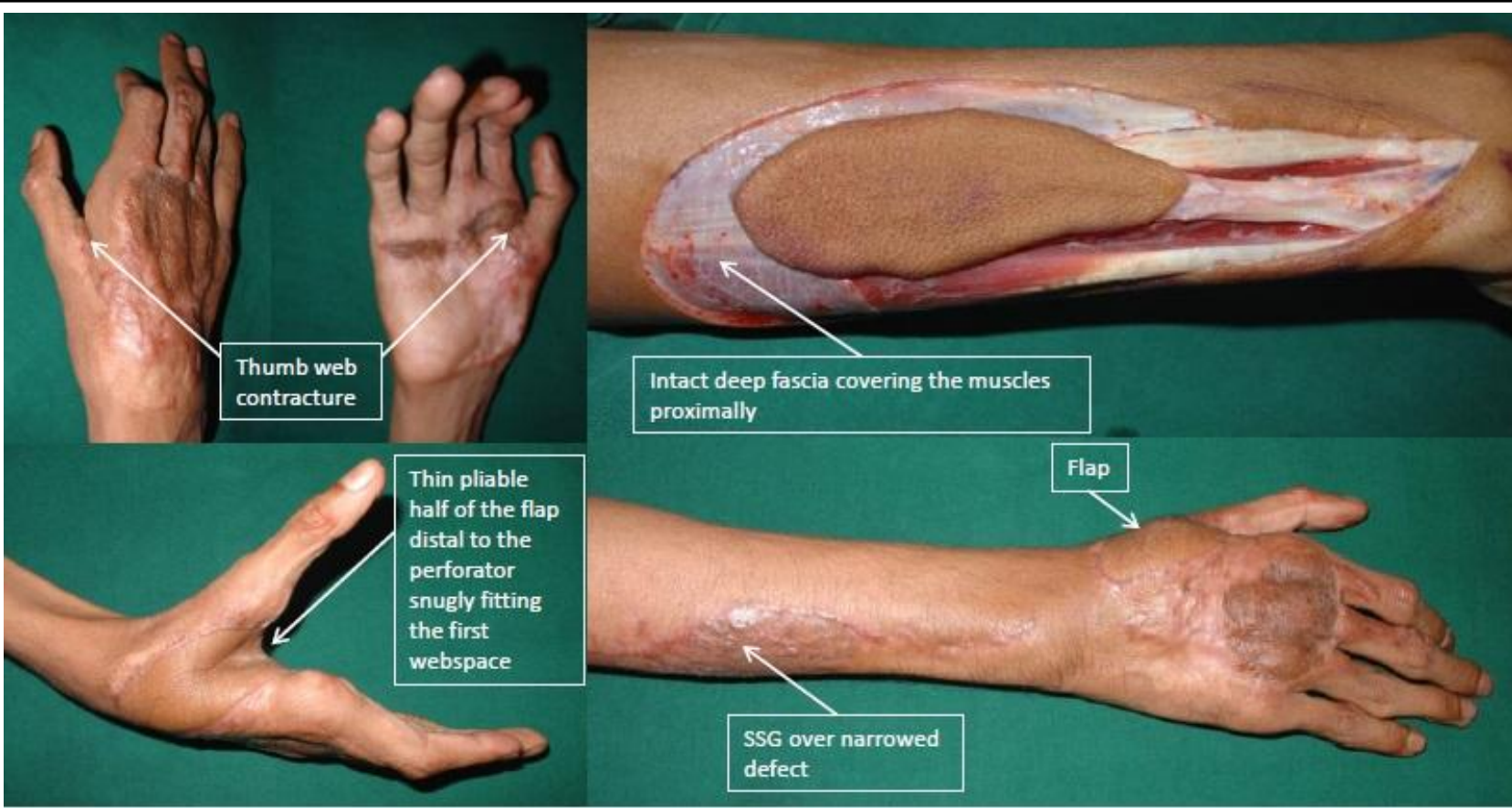

Figure 6: Case 2- Release of post-burn right thumb web contracture and PIA flap cover

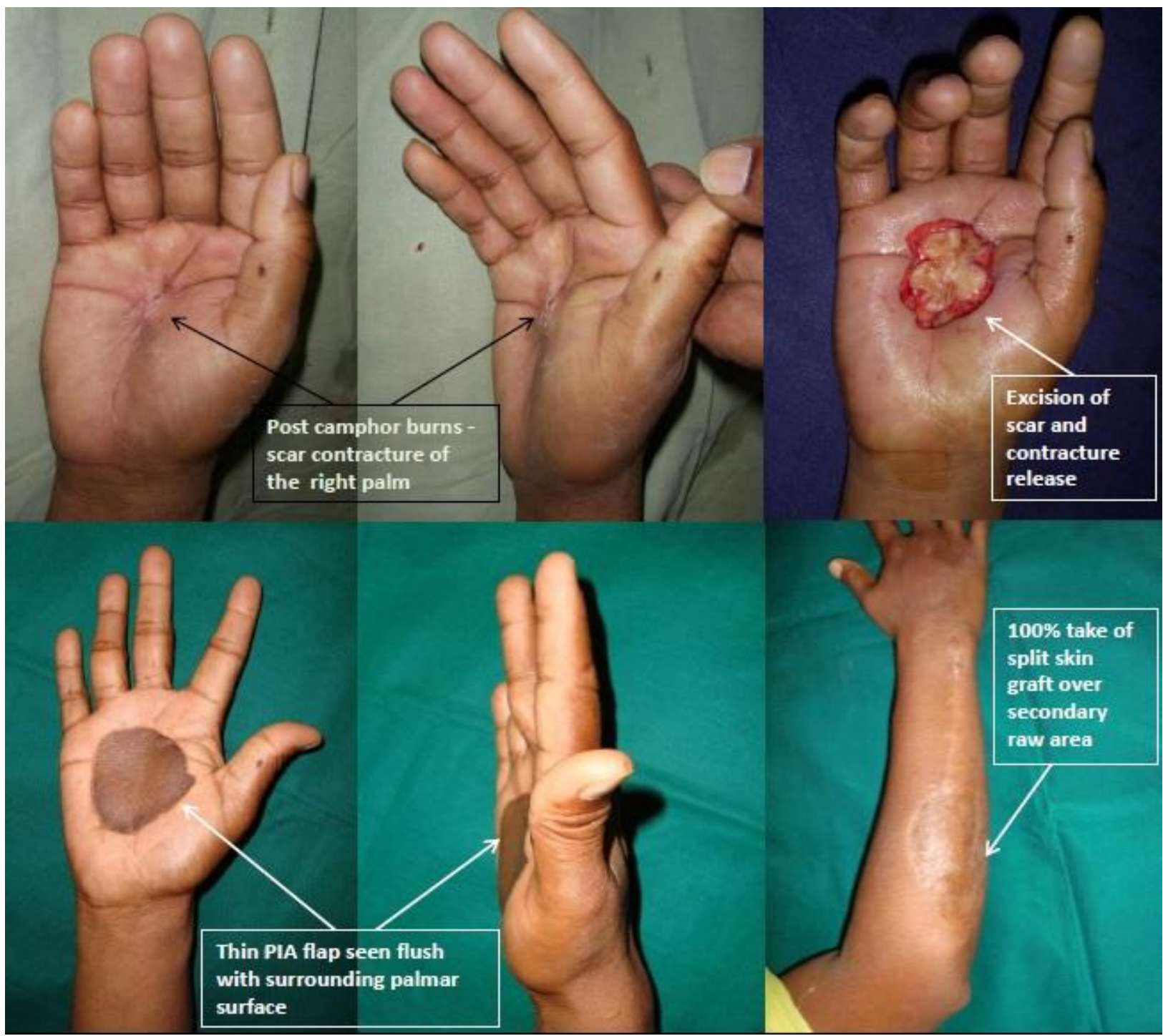

Figure 7: Case 3 - PIA flap for right palm defect following release of PBC due to camphor burn 


\section{JMSCR Vol||09||Issue ||07||Page 155-168||July}

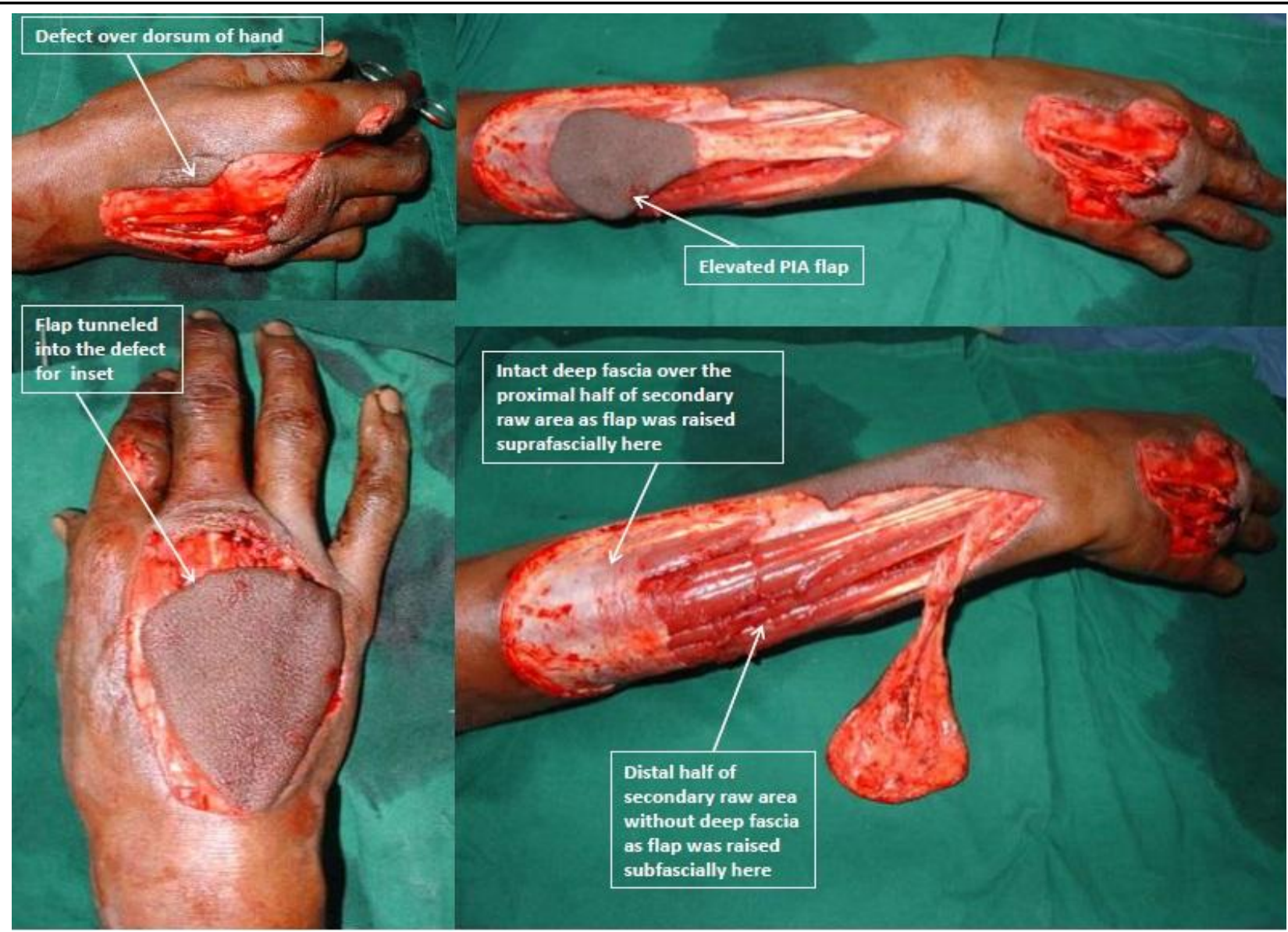

Figure 8: Case 4 - PIA for defect in dorsum of right hand following debridement of post-traumatic wound

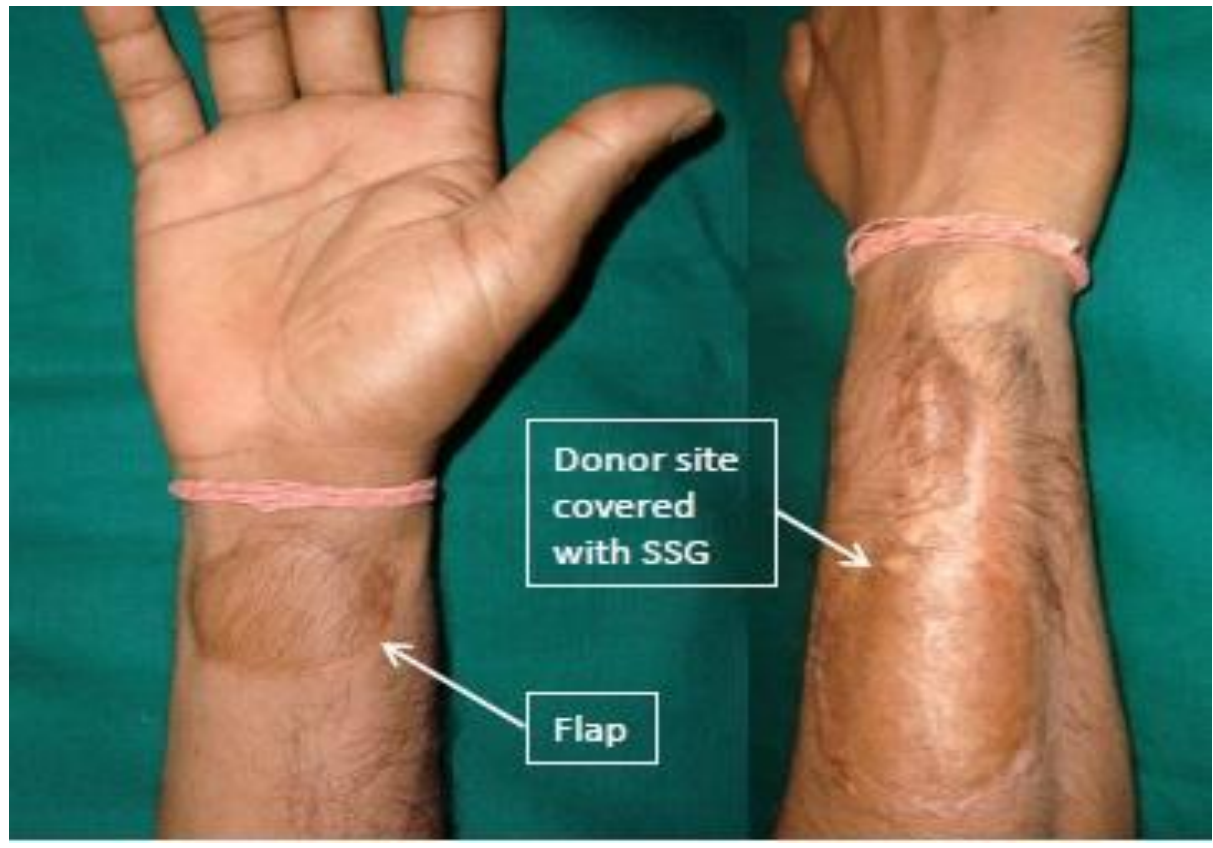

Figure 9: Case 5 - PIA flap for defect over volar aspect of right forearm following debridement of posttraumatic wound, tenorrhaphy and median nerve neurorrhaphy 


\section{JMSCR Vol||09||Issue||07||Page 155-168||July

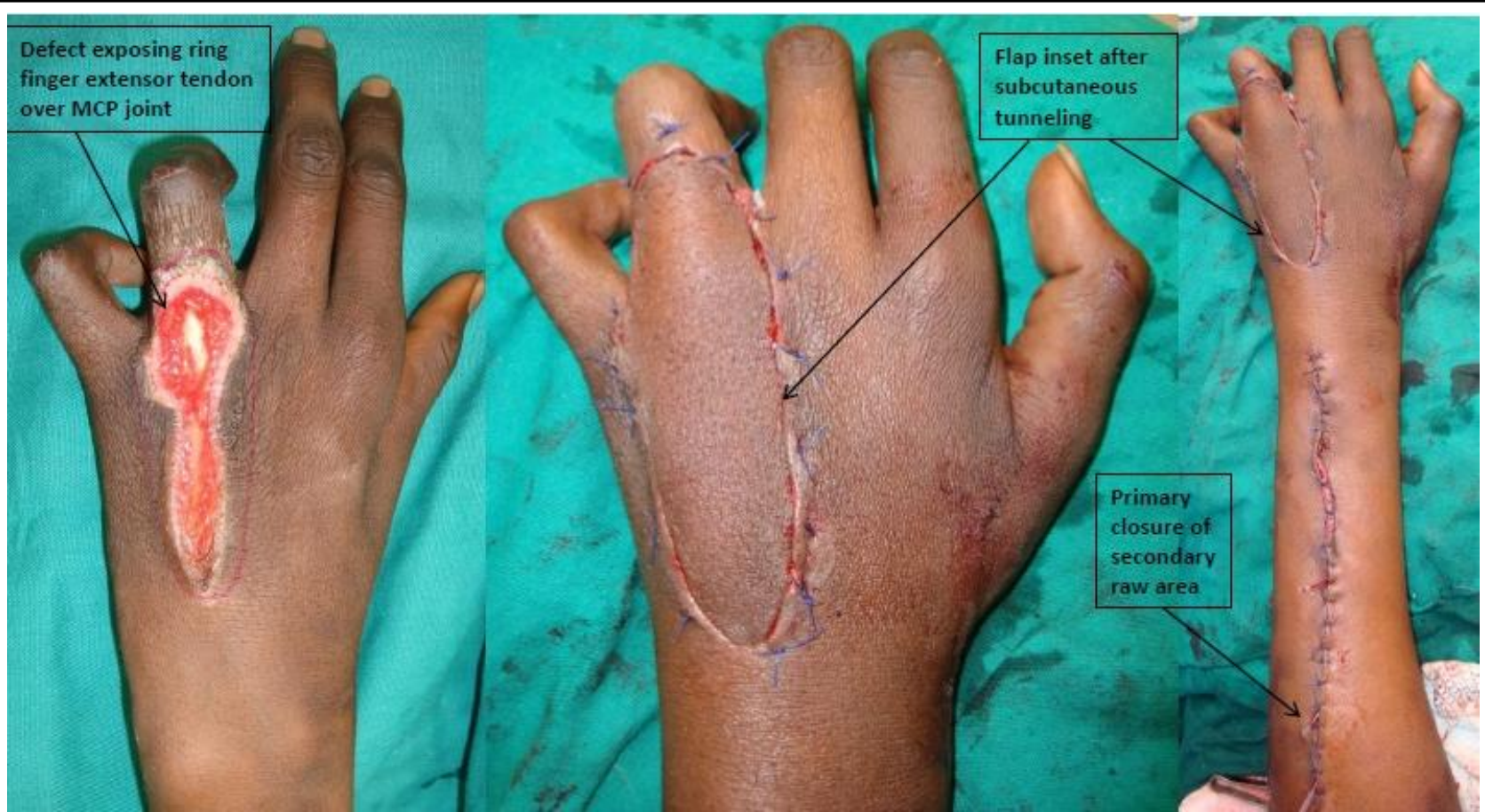

Figure 10: Case 6 - PIA flap for defect in dorsum of left hand exposing extensor tendon over MCP joint of ring finger

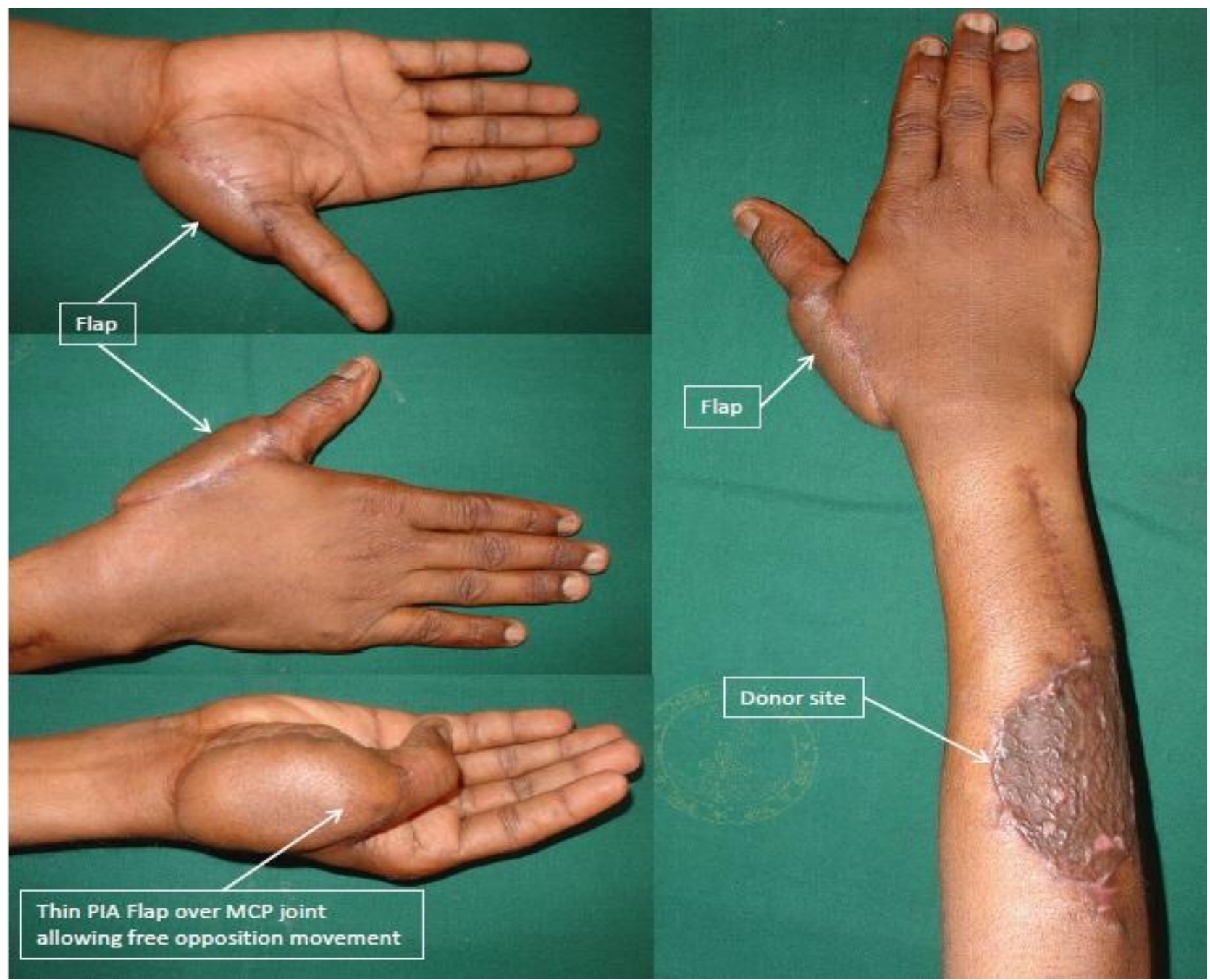

Figure 11: Case 7 - PIA flap for post-traumatic wound exposing right thumb MC and MCP joint 


\section{JMSCR Vol||09||Issue ||07||Page 155-168||July}

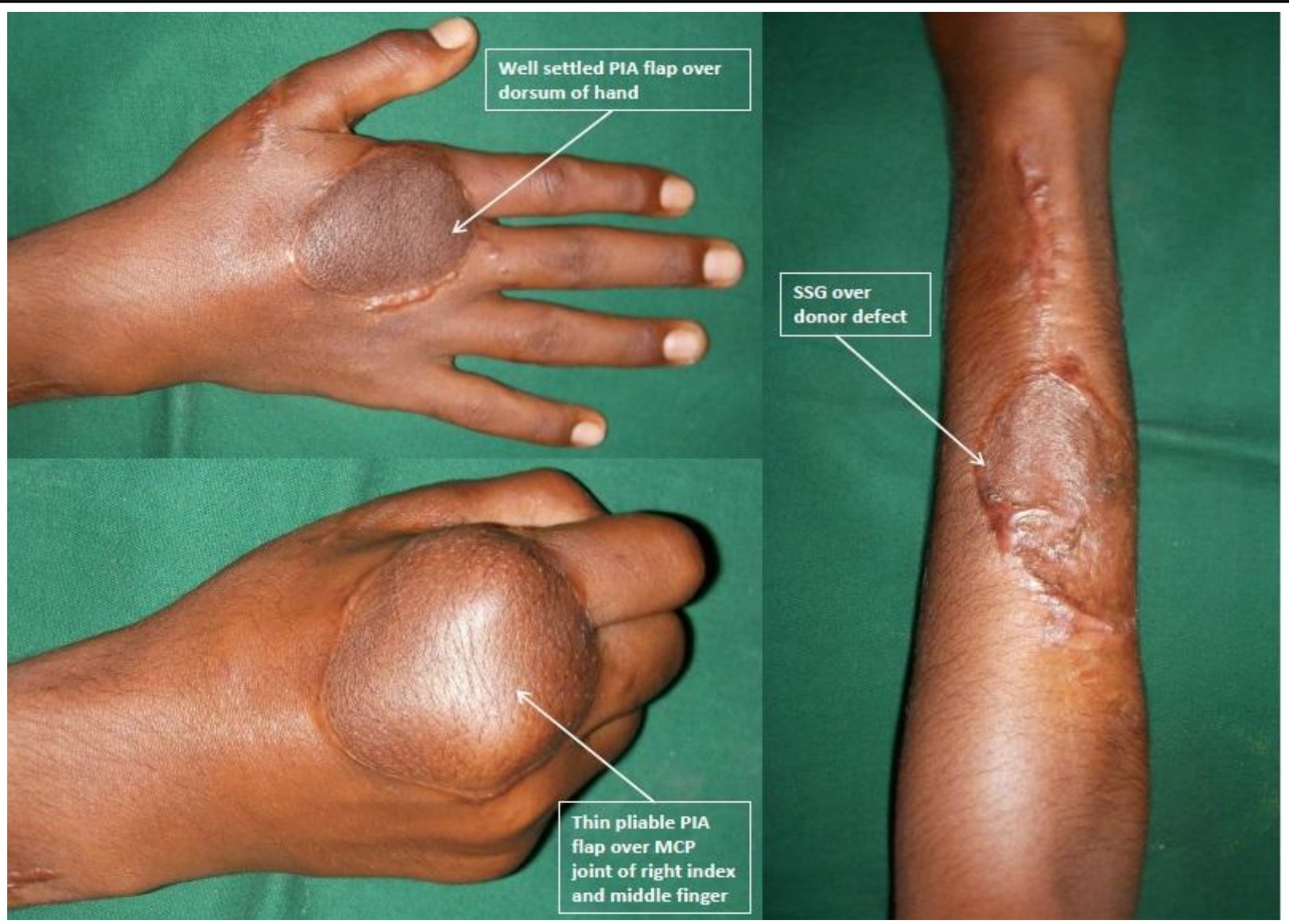

Figure 12: Case 8 - PIA flap for post-traumatic defect over dorsum of right hand, $2^{\text {nd }}$ and $3^{\text {rd }} \mathrm{MCP}$ joint

Table 1: Clinical details, operative and post-operative details of our patients

\begin{tabular}{|c|c|c|c|c|c|c|c|}
\hline $\begin{array}{l}\text { Sl. } \\
\text { No. }\end{array}$ & Age & Gender & Cause & Location & $\begin{array}{c}\text { Timing of } \\
\text { surgery }\end{array}$ & Procedure & Complication \\
\hline 1 & 36 & Female & PBC & Thumb-Z contracture & Elective & Contracture release and flap cover & None \\
\hline 2 & 51 & Male & $\mathrm{PBC}$ & $1^{\text {st }}$ web space & Elective & Contracture release and flap cover & None \\
\hline 3 & 35 & Female & $\begin{array}{l}\text { PBC- } \\
\text { Camphor } \\
\text { burn }\end{array}$ & Palm & Elective & Contracture release and flap cover & None \\
\hline 4 & 40 & Female & Trauma & Dorsum of hand & Emergency & Debridement and flap cover & None \\
\hline 5 & 46 & Male & Trauma & Distal forearm- volar & Emergency & $\begin{array}{c}\text { Debridement, tenorrhaphy, median } \\
\text { nerve repair and flap cover }\end{array}$ & None \\
\hline 6 & 33 & Female & Trauma & $\begin{array}{l}\text { Dorsum of hand and } \\
\text { middle finger distal to } \\
\text { MCP Joint }\end{array}$ & Elective & Debridement and flap cover & None \\
\hline 7 & 28 & Male & Trauma & Dorsum of thumb MC & Emergency & $\begin{array}{l}\text { K-wire fixation of thumb MC with } \\
\text { Flap cover }\end{array}$ & None \\
\hline 8 & 34 & Male & Trauma & $\begin{array}{c}\text { Hand- dorsum of } \\
\text { index\& middle finger } \\
\text { MCP joint }\end{array}$ & Emergency & Debridement and flap cover & None \\
\hline 9 & 61 & Female & Tumor & $\begin{array}{c}\text { Recurrent } \\
\text { Dermatofibro-sarcoma } \\
\text { Protuberans of hand }\end{array}$ & Elective & Wide local excision and flap cover & edema \\
\hline 10 & 55 & Female & Trauma & $\begin{array}{l}\text { Amputated stump of } \\
\text { thumb Exposing PPx }\end{array}$ & Emergency & Debridement and flap cover & None \\
\hline 11 & 37 & Male & Trauma & $\begin{array}{l}\text { Wrist joint - dorsal } \\
\text { aspect }\end{array}$ & Emergency & $\begin{array}{l}\text { Debridement, tenorrhaphy and flap } \\
\text { cover }\end{array}$ & None \\
\hline 12 & 44 & Male & $\mathrm{PBC}$ & $1^{\text {st }}$ web space & Elective & Contracture release and flap cover & None \\
\hline 13 & 42 & Male & Trauma & Hand- ulnar border & Emergency & Debridement and flap cover & $\begin{array}{c}\text { Venous } \\
\text { congestion }\end{array}$ \\
\hline 14 & 47 & Male & Trauma & $\begin{array}{l}\text { Wrist joint - volar } \\
\text { aspect }\end{array}$ & Emergency & Debridement, and flap cover & None \\
\hline 15 & 39 & Female & $\mathrm{PBC}$ & Thumb & Elective & Contracture release and flap cover & None \\
\hline
\end{tabular}

PBC- Post Burn Contracture; MC- Metacarpal; MCP-Metacarpo-Phalangeal Joint; PPx- Proximal Phalanx 


\section{Discussion}

PIA flap was initially introduced as a distally based retrograde flap for various soft tissue defects in the fingers, thumb, wrist, palm \& dorsum of the hand, and first web space ${ }^{(4,5,8)}$. This versatility has been shown in our study also. Various defects included in our study are enlisted in Table 1. A proximally-based PIA flap has also been described for elbow defects ${ }^{(9)}$ and to prevent the recurrence of synostosis of the elbow joint ${ }^{(10)}$. Post-traumatic defects and defects after post-burn contracture release form the majority of indications in most literature. In a few studies, it has also been utilized in the reconstruction of defects following excision of tumors like sarcoma $^{(11)}$. We have performed the PIA flap for one case of recurrent dermatofibrosarcoma after wide local excision.

The reverse PIA flap is based on the anastomosis between the PIA and the anterior interosseous artery (AIA) proximal to the wrist joint. A major advantage of PIA flap is that the main vessels of the forearm and hand, namely ulnar and radial artery can be spared ${ }^{(12)}$, and is available even in the presence of injury to these vessels. Many studies have confirmed variations and the absence of PIA occurring commonly in the midforearm ${ }^{(13)}$. Despite these variations, the versatility and reliability of PIA have been proved and it is a widely accepted flap ${ }^{(14)}$.

PIA arises as a branch of the common interosseous artery, just a centimeter after its origin from the ulnar artery and passes between the oblique cord and interosseous membrane to enter the posterior compartment between supinator and abductor pollicislongus muscle. The point of entrance is approximately at the junction of the upper third and middle third of the line joining lateral epicondyle and ulnar head ${ }^{(5)}$. It gives off an interosseous recurrent artery deep to supinator $^{(15)}$ and then runs down between the superficial and deep muscles of the posterior compartment of the forearm in the intermuscular septum between ECU and EDM. The PIA continues to run in the septum and at around $2 \mathrm{~cm}$ proximal to the DRUJ(13), its transverse branch anastomoses with the dorsal branch of AIA. PIA joins the Dorsal Intercarpal Arch (DIA) through the 5th extensor compartment artery (ECA) running on the radial side of the 5th extensor compartment floor ${ }^{(7)}$. Many anatomical studies have also documented anastomosis of PIA with the vascular plexus around the ulnar head or neck ${ }^{(8,13,16-18)}$. This branch was noticed in our dissection in all the cases, around the neck of the ulna and it was preserved to augment the blood supply of the retrograde PIA flap (Figure 4). Due to this inclusion, the pivot point got shifted $0.5 \mathrm{~cm}$ more proximally.

Seven to fourteen Perforators arising from PIA travel in the septum between ECU and EDM and supply the posterior forearm skin. Few authors describe that these perforators are in two groups, one in the middle forearm and the other in the distal forearm. We included the perforator in the mid-forearm. The flap was designed in such a way that the perforator was located eccentrically in its distal portion so that flap could have adequate reach. Even if the perforator was in the distal part of the skin island, the flap perfusion was good (the augmentation from the preserved ulnar artery branch to PIA). Though another perforator was generally available from PIA in the proximal forearm soon after its origin from Common Interosseous artery, we did not raise based on it, because 1) the reach for the defects after planning was found to be adequate with second perforator 2) the dissection becomes tedious proximally, because of the PIN which divides into multiple branches to supply the extensor muscles and is liable to injury. The PIN is located lateral to the PIA in the posterior compartment of the forearm ${ }^{(5)}$. Branches from the PIN to the extensor muscles arising from lateral epicondyle pass superficial to the interosseous recurrent artery. The branch to ECU might be closely associated with the most proximal relevant perforator. If the branch to ECU runs deep to PIA or proximal to the located perforator, the flap harvest is straightforward without any injury to the ECU 
branch. If the branch to ECU runs superficial and distal to the desired perforator, then the nerve to ECU has to be divided (close to the muscle) and repaired after the flap harvest. If unrepaired or sometimes even when repaired, paralysis or weakness of ECU muscle can result. None of our patients had ECU weakness. We did not encounter the ECU branch of PIN near our chosen perforator in the mid-forearm.

Initially, Angirgiani et al described it as a suprafascial flap ${ }^{(4)}$. But they encountered few partial and total flap necroses. Over a period of time fascia was included to improve the vascularity of the flap ${ }^{(19)}$. But this made the flap bulkier in contrast to the thin, pliable flap required in the recipient areas. To incorporate the advantages of both suprafascial and subfascial dissection, our surgical technique was modified to elevate the flap suprafascially proximal to the perforator and to include the fascia distal to the perforator (Figure $2 \& 3$ ). In this way, the flap proximal to the perforator, which reaches the distal part of the defect, remains thin and pliable. Venous drainage is also enhanced and pedicle kinking is minimized by maintaining the fascia around and distal to the perforator and in the adipofascial pedicle. The incidence of venous congestion leading to partial or total flap loss in the literature is between $3 \%$ and $37 \%{ }^{(20)}$. Only one patient $(6.67 \%)$ in our study had minimal venous congestion which was managed with conservative management. None of our patients had any flap necrosis.

Angrigiani et al had $8.8 \%$ necrosis in 80 patients due to insufficient vascularity ${ }^{(4)}$. Buchler et al had partial necrosis in $21 \%$ of their patients which they attributed to both venous congestion and ischemia ${ }^{(8)}$. There was no arterial insufficiency in our study. This shall also be attributed to the careful dissection near the wrist joint, not injuring the dorsal oblique branch from the ulnar artery that runs around the neck of the ulna and joins the PIA adding to its vascularity. Though the main source is the anastomotic dorsal branch from AIA, preservation of the dorsal ulnar branch to PIA enhances the blood supply of the flap,as the PIA caliber decreases distally towards its anastomosis with AIA. This shifts the pivot point $5 \mathrm{~mm}$ proximally but does not affect the reach of the flap significantly if the flap is planned carefully with allowance for the shift. If need be another $3 \mathrm{~mm}$ distal shift can be achieved by incising the periosteum of ulna as described in the surgical procedure.

Ghareeb et al studied the functional and cosmetic outcomes of PIA flap in which $10 \%$ of their patients had delayed graft uptake and $5 \%$ of their patients had graft loss ${ }^{(21)}$. In our patients the donor area was narrowed before covering with a skin graft and most of the distal part of the defect got primarily closed while narrowing. Further, leaving the fascia at the proximal part of the donor defect served as a good and even bed for skin grafting. In our study, SSG uptake in the secondary raw area was good over the retained fascia. Although PIA flap is considered a thin flap compared to distant flaps used for hand defects ${ }^{(22)}$, even little bulkiness in extremities are easily noticeable and aesthetically unappealing. Bulkiness in the palm, first web space, and joints can also be functionally disabling. Secondary debulking procedures are required in many cases for better aesthesis and function. 30\% of flaps were bulky in Buchler et al study ${ }^{(8)}$. Shibata et al studied free and pedicled PIA flaps and $19 \%$ of their patients required debulking procedure ${ }^{(23)}$. None of our patients required a secondary procedure of debulking due to our refinements in flap elevation. The flap proximal to the perforator elevated suprafascially was thin and supple to cover hand and finger defects. There was no difficulty in adducting thumb after 1 st web space reconstruction. Flaps used in the palm were flush with surrounding skin and there was no hindrance in grasping objects. One disadvantage is the lack of colour and texture match when used in the palm and volar aspect of the fingers. Also if the donor area in the forearm is hairy it is not ideal to use it in the palm. Overall our patients were functionally satisfied with this single-stage retrograde PIA flap cover. 


\section{Conclusion}

PIA is a versatile flap for the defects in the distal forearm and hand. Despite the anatomical variations, it is a reliable flap. Mid-forearm perforator can be chosen whenever feasible with appropriate flap design to avoid encountering PIN branches. Vascularity can be enhanced by maintaining the communicating vessels from the ulnar artery around the neck of the ulna. Meticulous dissection is required to preserve these vessels. When elevated suprafascially, it provides a thin and pliable flap cover. The PIA flap is a preferred single-stage option in covering mediumsized defects of the proximal hand and distal forearm, without sacrifice of the main vessels.

\section{Conflict of Interest: Nil \\ Funding: None}

\section{References}

1. Gavaskar AS. Posterior Interosseous Artery Flap for Resurfacing Posttraumatic Soft Tissue Defects of the Hand. HAND. 2010 Dec;5(4):397-402.

2. Dogra B, Singh M, Chakravarty B, Basu S. Posterior Interosseous Artery Flap for Hand Defects. Med J Armed Forces India. 2006 Jan;62(1):33-5.

3. Zancolli EA, Angrigiani C. Colgajo dorsal de antebrazo (en isla) (pediculo de vasos interoseos posteriores). Rev Assoc Arg Ortop Traumatol 1986;54:161e8.

4. Angrigiani C, Grilli D, Dominikow D, Zancolli EA. Posterior interosseous reverse forearm flap: experience with 80 consecutive cases. Plast Reconstr Surg 1993; 92: 285-93.1

5. Penteado C, Masquelet A, Chevrel J. The anatomic basis of the fascio-cutaneous flap of the posterior interosseous artery. Surg Radiol Anat. 1986 Dec;8(4):209-15.

6. Acharya AM, Bhat AK, Bhaskaran K, The Reverse Posterior Interosseous Flap (2012) Technical considerations in raising an easier and more reliable flap. JHS 37(3):575-582.

7. Zaidenberg EE, Farias-Cisneros E, Pastrana MJ, Zaidenberg CR. Extended Posterior Interosseous Artery Flap: Anatomical and Clinical Study. J Hand Surg. 2017 Mar;42(3):182-9.

8. Büchler U, Frey H-P. Retrograde posterior interosseous flap. J Hand Surg. 1991 Mar;16(2):283-92.

9. Zaidenberg EE, Zancolli P, Farias Cisneros E, Miller AG, Moreno R. Antegrade Posterior Interosseous Flap for Nonhealing Wounds of the Elbow: Anatomical and Clinical Study. Plast Reconstr Surg Glob Open [Internet]. 2018 Nov 7 [cited 2020 Aug 16];6(11). Available from: https://www.ncbi.nlm.nih.gov/pmc/articles /PMC6414117/

10. Jones ME, Rider MA, Hughes J, Tonkin MA. The use of a proximally based posterior interosseous adipofascial flap to prevent recurrence of synostosis of the elbow joint and forearm. The Journal of Hand Surgery, European Volume. 2007 Apr;32(2):143-147. DOI: 10.1016/j.jhsb.2006.09.004.

11. Wang J-Q, Cai Q-Q, Yao W-T, Gao S-T, Wang $\mathrm{X}$, Zhang P. Reverse Posterior Interosseous Artery Flap for Reconstruction of the Wrist and Hand after Sarcoma Resection: Pia Flaps for Sarcoma. Orthop Surg. 2013 Nov;5(4):250-4.

12. Chen HC, Tang YB, Chuang D, Wei FC, Noordhoff MS. Microvascular free posterior interosseous flap and a comparison with the pedicled posterior interosseous flap. Ann Plast Surg. 1996;36:542-50.

13. Eo SR, Hwang SH, Hong KY, Lim SA, Lee GJ. Revisiting the Posterior Interosseous Artery Flap. Arch Hand Microsurg. 2018;23(3):195. 
14. H C, A P, H Z. The posterior interosseous flap - a prime technique in hand reconstruction. The experience of 100 anatomical dissections and 102 clinical cases. J Plast Reconstr Aesthetic Surg JPRAS. 2007 May 16;60(7):740-7.

15. Prasad R, Balakrishnan TM. Role of Interosseous Recurrent Artery Perforators in the Posterior Interosseous Artery Flap. J Hand Microsurg. 2016 Sep 13;07(01):3641.

16. Sotereanos DG, Darlis NA, Dailiana ZH, Sarris IK, Malizos KN. A capsular-based vascularized distal radius graft for proximal pole scaphoid pseudarthrosis. J Hand Surg 2006;31A:580 -587

17. Sheetz KK, Bishop AT, Berger RA. The arterial blood supply of the distal radius and ulna and its potential use in vascularized pedicled bone grafts. J Hand Surg. 1995 Nov;20(6):902-14.

18. Xarchas KC, Chatzipapas C, Koukou O, Kazakos K. Upper limb flaps for hand reconstruction. 2004;70:9.

19. Kelly S, Pertierra G, Orbay JL, Vernon LL, Shah A. Versatility of the Posterior Interosseous Artery Flap in Outpatient. Advances in Plastic \& Reconstructive Surgery2018 March; 164.

20. Reyad KA, Shaker AA, Elbarbary AS, Sayed MA, Elghareeb MA. The Number of Perforators Included in Reversed Flow Posterior Interosseous Artery Flap: Does It Affect the Incidence of Venous Congestion? Plast Reconstr Surg Glob Open [Internet]. 2016 Dec 22 [cited 2020 Aug 16];4(12). Available from: https://www.ncbi.nlm.nih.gov/pmc/articles /PMC5222658/

21. Ghareeb Fouad M, Megahed Mohamed A, El Kashty Sherif M, LabebAlaa A, Abd El Kader Hesham K. H. Functional and cosmetic outcomes of posterior interosseous artery flap in reconstructing hand defects. Menoufia Medical Journal. 2018; 31(4):1375-1379

22. Naalla R, Chauhan S, Dave A, Singhal M. Reconstruction of post-traumatic upper extremity soft tissue defects with pedicled flaps: An algorithmic approach to clinical decision making. Chin J Traumatol. 2018 Dec 1;21(6):338-51.

23. Shibata M, Iwabuchi Y, Kubota S, Matsuzaki H. Comparison of free and reversed pedicled posterior interosseous cutaneous flaps. Plast Reconstr Surg. 1997 Mar;99(3):791-802. 